\author{
Rafaela Almeida da Silva \\ (D) https://orcid.org/0000-0001-9749-178X \\ Adriana Alves Nery ${ }^{b}$ \\ iD https://orcid.org/0000-0002-1093-1437 \\ Paulo Gilvane Lopes Penac \\ (D) https://orcid.org/0000-0001-9653-5509 \\ Marcela Andrade Rios ${ }^{d}$ \\ iD https://orcid.org/0000-0001-7180-2009 \\ Rafael Pereira de Paula \\ (iD) https://orcid.org/0000-0003-1800-1450
}

a Universidade Estadual do Sudoeste da Bahia (Uesb), Programa de PósGraduação em Enfermagem e Saúde (PPGES). Jequié, BA, Brasil.

b Universidade Estadual do Sudoeste da Bahia (Uesb), Departamento de Saúde. Jequié, BA, Brasil.

'Universidade Federal da Bahia (Ufba), Faculdade de Medicina da Bahia. Salvador, BA, Brasil.

dUniversidade Estadual da Bahia (Uneb), Departamento de Educação. Guanambi, BA, Brasil.

e Universidade Estadual do Sudoeste da Bahia (Uesb), Departamento de Ciências Biológicas. Jequié, BA, Brasil.

Contato:

Adriana Alves Nery

E-mail:

aanery@uesb.edu.br

Os autores informam que este trabalho foi realizado com apoio da Coordenação de Aperfeiçoamento de Pessoal de Nível Superior - Brasil (Capes), Código de financiamento 001, concedido em janeiro de 2017.

Os autores declaram que não há conflitos de interesse.

Os autores informam que o trabalho não foi apresentado em eventos científicos e que é baseado na dissertação de mestrado de Rafaela Almeida da Silva, intitulada Distúrbios musculoesqueléticos e pélvicos em marisqueiras, apresentada em 2018 ao Programa de Pós-Graduação em Enfermagem e Saúde da Universidade Estadual do Sudoeste da Bahia (Uesb).

\section{Sintomas musculoesqueléticos em catadoras de marisco}

\author{
Musculoskeletal symptoms in shellfish pickers
}

\section{Resumo}

Objetivo: estimar a prevalência de distúrbios musculoesqueléticos e de seus principais fatores de risco em catadoras de marisco em uma comunidade na Bahia. Métodos: estudo epidemiológico transversal descritivo, com dados coletados em 2017 e análise estatística descritiva. Resultados: foram entrevistadas 139 mulheres, com idade média de 44,3 anos: 66,9\% casadas, 89,2\% pardas/pretas, $93,5 \%$ com filhos, $57,6 \%$ com escolaridade até o fundamental incompleto, e com renda mensal média de $\mathrm{R} \$ 234,00$ (menos de US\$ 60). Predominaram trabalhadoras que exerciam a ocupação por um período $\leq 30$ anos $(58,3 \%)$, com carga horária diária de até 6 horas $(54,0 \%)$, sem pausa para almoçar $(89,9 \%)$, que carregavam até $25 \mathrm{~kg}$ em um dia de trabalho $(57,6 \%)$, por um período $\leq 60$ minutos $(73,5 \%)$, e que avaliaram as condições de trabalho como muito ruim/ruim (60,4\%). Todas relataram dores musculoesqueléticas e as principais queixas foram na região das costas. Evidenciaram-se como fatores de risco: excesso de movimento, muito tempo de trabalho com sobrecarga nos membros superiores, falta de descanso e ritmo de trabalho acelerado. Conclusão: as catadoras de marisco estão expostas a fatores de risco que as predispõem a lesões por esforço repetitivo e doenças relacionadas ao trabalho, o que pode explicar a alta prevalência constatada.

Palavras-chave: vigilância em saúde pública; saúde do trabalhador; sistema musculoesquelético; mulheres trabalhadoras; epidemiologia descritiva.

\begin{abstract}
Objective: to estimate the prevalence of musculoskeletal disorders and their main risk factors in shellfish pickers from a fishing community in the state of Bahia, Brazil. Methods: cross-sectional descriptive epidemiological study, with data collected in 2017 and a descriptive statistical analysis. Results: we interviewed 139 women, aged 44.3 on average: $66.9 \%$ were married, $89.2 \%$ had brown[parda]/ black skin color, $93.5 \%$ had children, $57.6 \%$ did not conclude elementary school, and had an average monthly income of $R \$ 234.00$ (less than US\$ 60.00). They had been working for up to 30 years in this occupation (58.3\%), with a daily working time of up to 6 hours (54.0\%), without lunch break (89.9\%), carrying up to $25 \mathrm{~kg}$ during a working day (57.6\%), for up to 60 minutes $(73.5 \%)$. They rated their working conditions as very bad or bad (60.4\%). All of them reported musculoskeletal pain, especially in the back region. The risk factors evidenced were: excessive movement, long working hours with overburden of the upper limbs, lack of rest and fast-paced work. Conclusion: shellfish pickers are exposed to risk factors that predispose them to repetitive strain injuries and work-related musculoskeletal disorders, which may explain the high prevalence observed.
\end{abstract}

Keywords: public health surveillance; occupational health; musculoskeletal system; working women; epidemiology, descriptive.

Recebido: 20/09/2019

Revisado: 07/01/2020

Aprovado: 18/02/2020 


\section{Introdução}

As atividades de pesca têm relevância econômica e social, pois são importante fonte de renda e subsistência para uma parte da população ${ }^{1}$.

No Brasil, a pesca artesanal é uma relevante modalidade de trabalho. Segundo dados do Ministério da Pesca e Aquicultura, de acordo com levantamento feito em 2009, existem mais de 833.205 pescadores artesanais no país. Contudo, acredita-se que esse número seja superior a 1 milhão ${ }^{2}$.

Essa atividade é praticada em grande parte do território nacional e o maior contingente de pescadores artesanais atua nos estados da região Nordeste do país. O setor pesqueiro concentra-se em duas atividades: a pesca e a mariscagem, nas quais geralmente se observa uma divisão de gênero, ou seja, os homens envolvem-se na pesca, enquanto as mulheres e as crianças na mariscagem. A Bahia tem 105.455 mil pescadores artesanais, dos quais grande parte dedica-se, parcial ou exclusivamente, à coleta artesanal de mariscos ${ }^{3}$.

Define-se catadora de marisco a trabalhadora informal que sobrevive da coleta e venda de maris$\cos ^{4}$. Embora o termo marisqueira seja comumente utilizado para designar a trabalhadora artesanal, trata-se de um coloquialismo, de forma que foi adotada a denominação catadoras de marisco, uma vez que é o termo técnico adequado.

A pesca artesanal caracteriza-se fundamentalmente pelo trabalho familiar de homens, mulheres e crianças, preservando as principais características do método praticado há muito tempo. Fundamenta-se em conhecimentos empíricos adquiridos em família e que se mantiveram por meio da transmissão oral dos membros mais velhos da comunidade. Resulta de uma atividade produtiva individual, com baixa divisão técnica, na qual o artesão ou artesã geralmente é proprietário de seus instrumentos laborais e sobrevive da venda do produto do seu trabalho, e não da sua força de trabalho ${ }^{3}$.

Embora inseridas em um setor financeiramente bem organizado, as comunidades que sobrevivem da pesca artesanal ainda estão em situação de vulnerabilidade socioeconômica, o que pode estar associado à própria atividade laboral, visto que dependem de um recurso natural limitado, atuam em um ambiente de trabalho instável e seu poder de venda é muito menor em relação à pesca industrial ${ }^{5}$.

As atividades laborais, às quais as catadoras de marisco estão expostas, geram sobrecarga articular e muscular em diversas regiões do corpo, podendo acarretar o surgimento de distúrbios musculoesqueléticos. Além disso, algumas etapas da mariscagem envolvem movimentos repetitivos, fator determinante para o surgimento de Lesões por Esforço Repetitivo (LER) e das Doenças
Osteomusculares Relacionadas ao Trabalho (Dort). Sendo assim, a atividade de mariscagem pode ocasionar danos à saúde dessas trabalhadoras ${ }^{6}$.

Os distúrbios musculoesqueléticos são um importante problema de saúde pública que vem aumentando nos últimos anos. Representam a doença ocupacional mais frequente, comprometendo a qualidade de vida dos trabalhadores e, consequentemente, sua empregabilidade. Além disso, também são responsáveis pela incapacidade funcional e absenteísmo ${ }^{7}$.

Segundo dados da Previdência Social, no Brasil os distúrbios musculoesqueléticos relacionados ao trabalho são as doenças proporcionalmente mais frequentes nos últimos anos, com maior acometimento de membros superiores e coluna vertebral ${ }^{8}$. Eles são um problema que ocorre em diversas atividades laborais, além de serem condições inflamatórias e degenerativas que acometem diferentes tipos de estruturas, tais como: músculos, nervos, ligamentos e diferentes articulações, entre as quais as mais atingidas são aquelas com maiores graus de amplitude ${ }^{9}$.

Os distúrbios musculoesqueléticos são de causa multifatorial. Contudo, são raros os estudos que investigam de forma conjunta os aspectos individuais, laborais, físicos e psicossociais do trabalho ${ }^{10}$.

Estudos vêm sendo desenvolvidos objetivando compreender o trabalho e as queixas musculoesqueléticas. No entanto, é necessário considerar a incipiência na literatura científica sobre tais distúrbios no trabalho informal, inclusive no processo de trabalho da catadora de marisco $6,11,12$.

Sendo assim, este estudo tem como objetivo estimar a prevalência de distúrbios musculoesqueléticos e de seus principais fatores de risco em catadoras de marisco da comunidade de Jiribatuba, no município de Vera Cruz, na Bahia.

\section{Métodos}

Trata-se de um estudo epidemiológico descritivo, de corte transversal, realizado com catadoras de marisco em uma comunidade da ilha de Jiribatuba, no município de Vera Cruz, na Bahia.

Participaram do estudo indivíduos do sexo feminino, uma vez que essa atividade é desenvolvida predominantemente pelas mulheres, com idade igual ou superior a 18 anos, com no mínimo um ano de atuação como catadora de marisco, e que dispunham de capacidades cognitivas que lhes permitissem ser incluídas no estudo.

A quantidade de catadoras de marisco que residem em Jiribatuba $(n=150)$ foi obtida com as lideranças locais, já que não foram encontrados dados censitários registrados que contivessem o número 
total de catadoras de marisco nessa localidade. Foram convidadas a participar da pesquisa todas as catadoras encontradas.

A pesquisa foi desenvolvida por apenas uma pesquisadora. Um estudo piloto foi realizado em junho de 2017 com 15 catadoras de marisco da comunidade de Barreiras de Jacuruna, pertencente ao município de Jaguaripe, Bahia.

Os dados foram coletados entre 14 de agosto e 3 de novembro de 2017, mediante entrevistas orientadas por um questionário composto por três blocos: (i) aspectos sociodemográficos; (ii) informações ocupacionais; e (iii) ritmo de trabalho ${ }^{11}$. Além disso, foi utilizado um questionário validado para avaliação de sintomas musculoesqueléticos ${ }^{13}$.

Neste estudo foram consideradas as seguintes variáveis sociodemográficas: faixa etária $(\leq 22$ anos, 23-43 anos, $\geq 44$ anos); estado marital (casadas, não casadas); escolaridade (ensino fundamental incompleto, ensino médio completo); raça/cor da pele (branca, preta, parda, outras); filhos ( $\mathrm{sim} /$ não); número de filhos $(<3, \geq 3$ ); tipo de parto (natural, cesárea, natural e cesárea); cadastro na colônia de pescadores (sim/não); cadastro em programa de transferência de renda ( $\operatorname{sim} /$ não); principal fonte de renda (mariscagem, pesca, programa de transferência de renda, outra); Índice de Massa Corporal (IMC) ${ }^{14}$ (peso normal $<25$, sobrepeso/obesidade $\geq 25$ ); circunferência abdominal $(<80 \mathrm{~cm}, \geq 80 \mathrm{~cm})$.

As variáveis relacionadas aos aspectos ocupacionais e às condições laborais foram: exercem outro tipo de atividade ( $\operatorname{sim} /$ não); tempo nessa ocupação ( $\leq 30$ anos, $>30$ anos); condições de trabalho (muito boa/boa, normal, muito ruim/ruim); nível de satisfação com o trabalho (muito satisfeita/satisfeita, nem insatisfeita/nem satisfeita, pouco satisfeita/insatisfeita); jornada de trabalho diária ( $\leq 6$ horas, $>6$ horas); jornada de trabalho semanal ( $\leq 40$ horas, $>40$ horas); pausa para almoço ( $\operatorname{sim} /$ não); trabalho com carteira assinada (sim/não); embarcação própria para coleta de marisco (sim/não); afastamento por motivo de doença ( $\operatorname{sim} /$ não); tipos de marisco que coleta $(\leq 6$ tipos, $>6$ tipos); peso que carrega ( $\leq 25 \mathrm{~kg},>25 \mathrm{~kg}$ ); tempo de transporte manual com peso $(\leq 60 \mathrm{~min}$, $>60 \mathrm{~min}$ ); retiradas de marisco por minuto $(\leq 17$, $>17$ ); e movimentos repetitivos por minuto $(\leq 10$ movimentos, $>10$ movimentos).

A maioria desses dados foi coletada por meio de autorrelato, exceto as variáveis peso (em quilogramas), altura (em metros) e circunferência abdominal (em centímetros). O IMC foi calculado como peso/altura ${ }^{2}$.

As demandas físicas para o trabalho elucidadas no bloco sobre o Ritmo de Trabalho foram avaliadas segundo as subetapas da mariscagem, como coleta, transporte, lavagem e limpeza, cozimento e cata dos mariscos. Nesse bloco foram analisadas as posturas em que exercem essas atividades: sentada, em pé, andando, agachada, com tronco inclinado para a frente, com tronco rodado e braços acima da altura dos ombros, além dos movimentos repetitivos e de motricidade fina, da força muscular envolvida no trabalho e do manuseio de carga. Tais variáveis apresentaram como opções de resposta uma escala de 0 a 5 relacionada a: pressão, com 0 representando inexistente e 5 insuportável; ritmo, com 0 representando lento e 5 muito acelerado; pausa, com 0 representando nunca e 5 quando precisa; postura e manuseio de carga, com 0 representando jamais e 5 o tempo todo; força, com 0 representando muito fraca e 5 muito forte.

Para avaliar os sintomas musculoesqueléticos foi utilizado o Nordic Musculoskeletal Questionnaire (NMQ). As entrevistadas responderam a perguntas simples (sim ou não) tanto em relação à dor quanto ao desconforto apresentado antes da pesquisa (últimos 12 meses) e/ou atualmente (últimos 7 dias). Além disso, responderam sobre a ocorrência de incapacidade funcional e sobre a procura por atendimento profissional de saúde nos últimos 12 meses devido aos sintomas musculoesqueléticos. Foram consideradas portadoras de distúrbios musculoesqueléticos aquelas em que os sintomas estiveram associados a um dos seguintes itens de gravidade: grau de severidade $\geq 3$, em uma escala de 0 a 5 (sendo 0 nenhum desconforto e 5 desconforto insuportável), busca de atenção profissional por causa do problema, ausência ao trabalho ou mudança de trabalho por restrição de saúde ${ }^{13}$.

Os dados foram analisados com auxílio do programa estatístico SPSS, versão 21.0, por meio do cálculo de estatísticas descritivas: frequências absolutas e relativas para as variáveis categóricas e medida de tendência central (média) e de dispersão (desvio-padrão (DP) para as variáveis quantitativas.

O estudo foi aprovado pelo Comitê de Ética em Pesquisa da Faculdade Adventista da Bahia, campus de Cachoeira, sob parecer $n^{\circ}$ 2.064.056, em 15 de maio de 2017. Todas as participantes receberam esclarecimento sobre a pesquisa e assinaram o Termo de Consentimento Livre e Esclarecido.

\section{Resultados}

Das 150 catadoras abordadas, 139 participaram do estudo: uma não tinha condições cognitivas adequadas à compreensão do estudo e dez recusaram.

Todas as participantes moravam em Jiribatuba, de onde a maioria era natural (54\%); com idade entre 21 e 70 anos e idade média de 44,3 anos (desvio-padrão 11,3). Predominaram trabalhadoras casadas $(66,9 \%)$ e com ensino fundamental incompleto $(57,6 \%)$, dentre as quais 6,4\% não tinham ensino formal. Quanto à raça/cor, autodeclararam-se na mesma proporção 
como pardas e pretas $44,6 \%$ das mulheres. A renda mensal média declarada foi de $\mathrm{R} \$ 234,00$ (amplitude 200-500, desvio-padrão 71,4).

Quanto a ter filhos, 93,5\% responderam sim, com predomínio de até três filhos (59,7\%), em sua maioria nascidos de parto natural $(65,4 \%)$. Em média, corresidiam com quatro pessoas (desvio-padrão 2), todas em casa própria e de alvenaria, com sistema de saneamento do tipo fossa rudimentar. Grande parte dessas trabalhadoras $(78,4 \%)$ estava cadastrada na Colônia de Pescadores de Jiribatuba (da qual faziam parte as catadoras de marisco). Quanto à inserção em programas de transferência de renda, 62,6\% recebiam algum auxílio. A maioria $(55,4 \%)$ mantinha a casa com o dinheiro proveniente da mariscagem e $57,4 \%$ relataram que esse rendimento era suficiente para sustentar a família (Tabela 1).

Das catadoras de marisco, 69,8\% apresentaram IMC $\geq 25$ e $59,7 \%$ CA $\geq 80 \mathrm{~cm}$, sendo consideradas, segundo a Organização Mundial de Saúde, com sobrepeso/obesas ${ }^{14}$ (Tabela 1).

Tabela 1 Caracterização sociodemográfica das catadoras de marisco de Jiribatuba, Vera Cruz, Bahia, 2017

\begin{tabular}{|c|c|c|}
\hline Variáveis & $n$ (139) & $\%$ \\
\hline \multicolumn{3}{|l|}{ 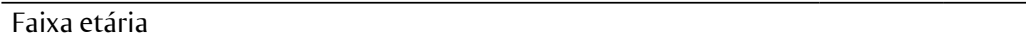 } \\
\hline Até 22 anos & 4 & 2,9 \\
\hline 23 a 43 anos & 67 & 48,2 \\
\hline$\geq 44$ & 68 & 48,9 \\
\hline \multicolumn{3}{|l|}{ Estado marital } \\
\hline Casadas & 93 & 66,9 \\
\hline Não casadas & 46 & 33,1 \\
\hline \multicolumn{3}{|l|}{ Escolaridade } \\
\hline Ensino Fundamental incompleto & 80 & 57,6 \\
\hline Ensino Médio completo & 59 & 42,4 \\
\hline \multicolumn{3}{|l|}{ Raça/cor } \\
\hline Preta & 62 & 44,6 \\
\hline Branca & 4 & 2,9 \\
\hline Parda & 62 & 44,6 \\
\hline Outros & 11 & 7,9 \\
\hline \multicolumn{3}{|l|}{ Filhos } \\
\hline Sim & 130 & 93,5 \\
\hline Não & 9 & 6,5 \\
\hline \multicolumn{3}{|l|}{ Número de filhos } \\
\hline$\leq 3$ & 83 & 59,7 \\
\hline$>3$ & 56 & 40,3 \\
\hline \multicolumn{3}{|l|}{ Cadastro na colônia de pescadores } \\
\hline Sim & 109 & 78,4 \\
\hline Não & 30 & 21,6 \\
\hline \multicolumn{3}{|c|}{ Cadastro em algum programa de auxílio do governo } \\
\hline Sim & 87 & 62,6 \\
\hline Não & 52 & 37,4 \\
\hline \multicolumn{3}{|l|}{ Principal fonte de renda } \\
\hline Mariscagem & 77 & 55,4 \\
\hline Pesca & 10 & 7,2 \\
\hline Auxílio do governo & 8 & 5,7 \\
\hline Outros & 44 & 31,7 \\
\hline \multicolumn{3}{|l|}{ IMC } \\
\hline Peso normal (IMC $\left.<25 \mathrm{~kg} / \mathrm{m}^{2}\right)$ & 42 & 30,2 \\
\hline Sobrepeso/Obesidade (IMC $\left.\geq 25 \mathrm{~kg} / \mathrm{m}^{2}\right)$ & 97 & 69,8 \\
\hline \multicolumn{3}{|l|}{ Circunferência abdominal } \\
\hline$<80 \mathrm{~cm}$ & 56 & 40,3 \\
\hline$\geq 80 \mathrm{~cm}$ & 83 & 59,7 \\
\hline
\end{tabular}


Quanto aos aspectos ocupacionais, predominaram catadoras de marisco que exerciam essa ocupação em período $\leq 30$ anos (58,3\%), cumprindo carga horária diária de até seis horas $(54,0 \%)$, carga horária semanal de até 40 horas (81,3\%), que não tinham pausa para almoçar $(89,9 \%)$ e que nunca trabalharam formalmente registradas, com carteira assinada (84,2\%) (Tabela 2).

No que diz respeito às condições em que trabalhavam, a maioria $(60,4 \%)$ declarou serem muito ruins/ruins e que estava muito satisfeita/satisfeita em ser catadora de marisco $(56,1 \%)$, além de apresentar histórico de afastamento por motivo de doença (59,7\%) (Tabela 2).

A maior parte das catadoras de marisco não tinha embarcação própria $(77,0 \%)$, coletava até seis tipos de marisco $(79,1 \%)$, realizando até 17 retiradas por minuto $(61,2 \%)$, com até dez movimentos repetitivos por minuto $(74,8 \%)$; a maioria chegava a carregar até $25 \mathrm{~kg}$ em um dia de trabalho $(57,6 \%)$, por um período $\leq 60$ minutos $(73,5 \%)$ (Tabela 2).

Tabela 2 Aspectos ocupacionais e condições laborais das catadoras de marisco de Jiribatuba, Vera Cruz, Bahia, 2017

\begin{tabular}{|c|c|c|}
\hline Variáveis & $n(139)$ & $\%$ \\
\hline \multicolumn{3}{|l|}{ Outro tipo de atividade } \\
\hline Sim & 13 & 9,4 \\
\hline Não & 126 & 90,6 \\
\hline \multicolumn{3}{|l|}{ Tempo nessa ocupação } \\
\hline$\leq 30$ anos & 81 & 58,3 \\
\hline$>30$ anos & 58 & 41,7 \\
\hline \multicolumn{3}{|c|}{ Considera suas condições de trabalho } \\
\hline Muito boa/boa & 11 & 7,9 \\
\hline Normal & 44 & 31,7 \\
\hline Muito ruim/ruim & 84 & 60,4 \\
\hline \multicolumn{3}{|l|}{ Nível de satisfação com o trabalho } \\
\hline Muito satisfeita/satisfeita & 78 & 56,1 \\
\hline Nem insatisfeita/nem satisfeita & 20 & 14,4 \\
\hline Pouco satisfeita/insatisfeita & 41 & 29,5 \\
\hline \multicolumn{3}{|l|}{ Jornada de trabalho diária } \\
\hline$\leq 6$ horas & 75 & 54,0 \\
\hline$>6$ horas & 64 & 46,0 \\
\hline \multicolumn{3}{|l|}{ Jornada de trabalho semanal } \\
\hline$\leq 40$ horas & 113 & 81,3 \\
\hline$>40$ horas & 26 & 18,7 \\
\hline \multicolumn{3}{|l|}{ Pausa para almoço } \\
\hline Sim & 14 & 10,1 \\
\hline Não & 125 & 89,9 \\
\hline \multicolumn{3}{|c|}{ Trabalho com carteira assinada (registro formal) } \\
\hline Sim & 22 & 15,8 \\
\hline Não & 117 & 84,2 \\
\hline \multicolumn{3}{|c|}{ Tem embarcação para coleta dos mariscos } \\
\hline Sim & 32 & 23,0 \\
\hline Não & 107 & 77,0 \\
\hline \multicolumn{3}{|l|}{ Já foi afastada por motivo de doença } \\
\hline Sim & 83 & 59,7 \\
\hline Não & 56 & 40,3 \\
\hline \multicolumn{3}{|l|}{ Tipos de marisco } \\
\hline$\leq 6$ tipos & 110 & 79,1 \\
\hline$>6$ tipos & 29 & 20,9 \\
\hline \multicolumn{3}{|l|}{ Peso que carregam $(n=99)$} \\
\hline$\leq 25 \mathrm{~kg}$ & 57 & 57,6 \\
\hline$>25 \mathrm{~kg}$ & 42 & 42,4 \\
\hline \multicolumn{3}{|c|}{ Tempo de transporte manual com peso $(n=102)$} \\
\hline$\leq 60$ minutos & 75 & 73,5 \\
\hline$>60$ minutos & 27 & 26,5 \\
\hline \multicolumn{3}{|l|}{ Retirada de mariscos por minuto } \\
\hline$\leq 17$ & 85 & 61,2 \\
\hline$>17$ & 54 & 38,8 \\
\hline \multicolumn{3}{|l|}{ Movimentos repetitivos por minuto } \\
\hline$\leq 10$ movimentos & 104 & 74,8 \\
\hline$>10$ movimentos & 35 & 25,2 \\
\hline
\end{tabular}


A Tabela 3 apresenta as demandas físicas laborais (média; desvio-padrão) segundo as etapas da mariscagem. As maiores demandas relatadas pelas catadoras de marisco, na etapa da coleta, ocorreram com movimentos repetitivos com as mãos e movimentos finos de controle e destreza, ou seja, movimentos de motricidade fina $(4,96 ; 0,43)$, com exigência de força muscular nos braços ou nas mãos $(4,71 ; 0,85)$ e pressão física com as mãos ao utilizar as ferramentas de trabalho $(4,06 ; 0,72)$.

Durante o transporte dos mariscos, as maiores demandas foram a exigência de força muscular nos braços ou nas mãos $(4,71 ; 0,93)$, e a pressão física com as mãos ao utilizar as ferramentas de trabalho $(3,95 ; 0,96)$. Na lavagem e limpeza dos mariscos, as exigências físicas mais expressivas ocorreram nos movimentos que precisam de maior destreza e controle $(4,80 ; 0,94)$; nos movimentos repetitivos com as mãos $(4,78 ; 1,02)$ e na postura em pé $(3,01$; $2,11)$. Na etapa de cozimento a maior demanda se referia à postura em pé $(4,65 ; 1,00)$, enquanto na etapa de cata as maiores demandas físicas ocorreram nos movimentos repetitivos com as mãos, nos de motricidade fina $(4,89 ; 0,72)$ e na postura sentada $(4,82 ; 0,86)$ (Tabela 3$)$.

A Tabela 4 apresenta a prevalência de queixas musculoesqueléticas por segmento corporal nos 12 meses antes da pesquisa e/ou nos sete dias que a antecederam. As queixas mais comumente relatadas nos últimos 12 meses se referiam à região inferior das costas $(83,6 \%)$, parte superior das costas $(84,2 \%)$, quadril/coxas $(79,1 \%)$, ombros $(77 \%)$, joelhos $(75,5 \%)$ e punhos/mãos $(74,8 \%)$.

Quanto ao impedimento de realizar atividades normais devido a essas queixas, como o trabalho ou atividades domésticas e de lazer, houve maior percentual de respostas afirmativas em todos os segmentos corporais, com destaque para punhos e mãos $(69,2 \%)$. As queixas em todos os segmentos levaram a maioria das catadoras de marisco à procura de algum profissional de saúde, principalmente as queixas de dores na região do cotovelo $(73,0 \%)$ e punhos/mãos (68,3\%). Em relação a problemas nos últimos sete dias, houve maior desconforto nas costas, tanto na região superior $(61,2 \%)$ como na inferior $(60,4 \%)$ (Tabela 4).

Tabela 3 Demandas físicas segundo as principais etapas de trabalho, classificadas em escala de 0 a $5^{*}$ pelas catadoras de marisco de Jiribatuba, Vera Cruz, Bahia, 2017

\begin{tabular}{|c|c|c|c|c|c|}
\hline Variáveis de demanda física & $\begin{array}{c}\text { Coleta } \\
\text { Média; } D P^{* * *}\end{array}$ & $\begin{array}{l}\text { Transporte } \\
\text { Média; } D P^{* * * *}\end{array}$ & $\begin{array}{c}\text { Lavagem e limpeza } \\
\text { Média; } D P^{* * * *}\end{array}$ & $\begin{array}{l}\text { Cozimento } \\
\text { Média; } D P^{* * * *}\end{array}$ & $\begin{array}{c}\text { Cata } \\
\text { Média; } D P^{* * * * *}\end{array}$ \\
\hline \multicolumn{6}{|l|}{ Posturas } \\
\hline Sentada & 1,$07 ; 1,59$ & 2,$19 ; 2,33$ & 0,$29 ; 096$ & 0,$24 ; 1,02$ & 4,$82 ; 0,86$ \\
\hline Em pé & 0,$94 ; 1,47$ & 0,$58 ; 1,47$ & 3,$01 ; 2,11$ & 4,$65 ; 1,00$ & 0,$08 ; 0,43$ \\
\hline Andando & 1,$33 ; 1,65$ & 2,$95 ; 2,25$ & 0,$10 ; 0,61$ & 0,$70 ; 1,23$ & 0,$03 ; 0,33$ \\
\hline Agachada & 3,$58 ; 1,29$ & 0,$08 ; 0,53$ & 2,$22 ; 1,94$ & 0,$02 ; 0,18$ & 0,$24 ; 0,96$ \\
\hline Com tronco inclinado para a frente & 3,$79 ; 1,23$ & 0,$09 ; 0,60$ & 0,$50 ; 1,32$ & 0,$04 ; 0,35$ & 0,$19 ; 0,89$ \\
\hline Com tronco rodado & 0,$24 ; 0,95$ & 0,$06 ; 0,49$ & 0,$07 ; 0,52$ & 0,$04 ; 0,30$ & 0,$08 ; 0,55$ \\
\hline Braços acima da altura dos ombros & 2,$65 ; 1,86$ & 1,$68 ; 2,05$ & 0,$00 ; 0,00$ & 0,$02 ; 0,25$ & 0,$04 ; 0,42$ \\
\hline Movimentos repetitivos com as mãos & 4,$96 ; 0,43$ & 0,$23 ; 1,02$ & 4,$78 ; 1,02$ & 0,$17 ; 0,85$ & 4,$89 ; 0,72$ \\
\hline Movimentos precisos e muito finos & 4,$96 ; 0,43$ & 0,$24 ; 1,04$ & 4,$80 ; 0,94$ & 0,$15 ; 0,84$ & 4,$89 ; 0,72$ \\
\hline \multicolumn{6}{|l|}{ Força muscular } \\
\hline Força muscular nos braços ou mãos & 4,$71 ; 0,85$ & 4,$71 ; 0,93$ & 2,$04 ; 0,83$ & 1,$71 ; 0,86$ & 2,$42 ; 0,81$ \\
\hline $\begin{array}{l}\text { Pressão física com as mãos ao utilizar as } \\
\text { ferramentas de trabalho }\end{array}$ & 4,$06 ; 0,72$ & 3,$95 ; 0,96$ & 2,$43 ; 1,10$ & 1,$55 ; 1,05$ & 2,$68 ; 0,76$ \\
\hline \multicolumn{6}{|l|}{ Manuseio de carga } \\
\hline Levantar & 3,$47 ; 0,60$ & 3,$36 ; 0,65$ & 2,$16 ; 1,00$ & 1,$10 ; 0,74$ & 2,$01 ; 0,88$ \\
\hline Puxar & 3,$27 ; 0,72$ & 3,$22 ; 0,68$ & 2,$06 ; 0,93$ & 1,$14 ; 0,75$ & 1,$99 ; 0,91$ \\
\hline Empurrar & 3,$31 ; 0,71$ & 3,$21 ; 0,69$ & 2,$06 ; 0,93$ & 1,$07 ; 0,71$ & 1,$99 ; 0,91$ \\
\hline
\end{tabular}

* Na escala adotada, nas variáveis postura e manuseio de carga 0 representa jamais e 5 o tempo todo. Na variável força muscular 0 representa muito fraca e 5 muito forte. ${ }^{* * *}$ DP: Desvio Padrão 
Tabela 4 Prevalência de queixas musculoesqueléticas por segmento corporal em catadoras de mariscos de Jiribatuba, Vera Cruz, Bahia, 2017

\begin{tabular}{|c|c|c|c|c|c|c|c|c|}
\hline \multirow{3}{*}{ Segmento corporal } & \multicolumn{6}{|c|}{ Problemas nos 12 meses anteriores à pesquisa } & \multicolumn{2}{|c|}{$\begin{array}{l}\text { Problema nos sete dias } \\
\text { anteriores à pesquisa }\end{array}$} \\
\hline & \multicolumn{2}{|c|}{$\begin{array}{l}\text { Dor/formigamento/ } \\
\text { dormência }\end{array}$} & \multicolumn{2}{|c|}{$\begin{array}{c}\text { Impedimento de realizar } \\
\text { atividades }\end{array}$} & \multicolumn{2}{|c|}{ Procurou serviço de saúde } & \multirow[b]{2}{*}{$n$ (139) } & \multirow[b]{2}{*}{$\%$} \\
\hline & $n(139)$ & $\%$ & $n(*)$ & $\%$ & $n($ (*⿻丷木) & $\%$ & & \\
\hline \multicolumn{9}{|l|}{ Pescoço } \\
\hline Sim & 99 & 71,2 & 63 & 63,6 & 61 & 62,2 & 53 & 38,1 \\
\hline Não & 40 & 28,8 & 36 & 36,4 & 37 & 37,8 & 86 & 61,9 \\
\hline \multicolumn{9}{|l|}{ Ombros } \\
\hline Sim & 107 & 77,0 & 73 & 68,2 & 71 & 66,4 & 61 & 43,9 \\
\hline Não & 32 & 23,0 & 34 & 31,8 & 36 & 33,6 & 78 & 56,1 \\
\hline \multicolumn{9}{|c|}{ Parte superior das costas } \\
\hline Sim & 117 & 84,2 & 78 & 67,2 & 74 & 64,3 & 85 & 61,2 \\
\hline Não & 22 & 15,8 & 38 & 32,8 & 41 & 35,7 & 54 & 38,8 \\
\hline \multicolumn{9}{|l|}{ Cotovelos } \\
\hline Sim & 62 & 44,6 & 41 & 66,1 & 46 & 73,0 & 45 & 32,4 \\
\hline Não & 77 & 55,4 & 21 & 33,9 & 17 & 27,0 & 94 & 67,6 \\
\hline \multicolumn{9}{|l|}{ Punhos/mãos } \\
\hline Sim & 104 & 74,8 & 72 & 69,2 & 71 & 68,3 & 59 & 42,4 \\
\hline Não & 35 & 25,2 & 32 & 30,8 & 33 & 31,7 & 80 & 57,6 \\
\hline \multicolumn{9}{|c|}{ Parte inferior das costas } \\
\hline Sim & 120 & 86,3 & 81 & 67,5 & 77 & 64,7 & 84 & 60,4 \\
\hline Não & 19 & 13,7 & 39 & 32,5 & 42 & 35,3 & 55 & 39,6 \\
\hline \multicolumn{9}{|l|}{ Quadril/coxas } \\
\hline Sim & 110 & 79,1 & 71 & 64,5 & 68 & 62,4 & 67 & 48,2 \\
\hline Não & 29 & 20,9 & 39 & 35,5 & 41 & 37,6 & 72 & 51,8 \\
\hline \multicolumn{9}{|l|}{ Joelhos } \\
\hline Sim & 105 & 75,5 & 70 & 66,7 & 68 & 65,4 & 66 & 47,5 \\
\hline Não & 34 & 24,5 & 35 & 33,3 & 36 & 34,6 & 73 & 52,5 \\
\hline \multicolumn{9}{|l|}{ Tornozelos/pés } \\
\hline Sim & 95 & 68,3 & 63 & 66,3 & 63 & 66,3 & 54 & 38,8 \\
\hline Não & 44 & 31,7 & 32 & 33,7 & 32 & 33,7 & 85 & 61,2 \\
\hline
\end{tabular}

Perdas: * Impedimento de realizar atividades: pescoço $(n=40)$; ombros $(n=32)$; parte superior das costas $(n=23)$; cotovelos ( $n=77)$; punhos/mãos $(\mathrm{n}=35)$; parte inferior das costas $(\mathrm{n}=19)$; quadril/coxas $(\mathrm{n}=29)$; joelhos $(\mathrm{n}=34)$; tornozelo e pé $(\mathrm{n}=44)$. $*$ *** Procurou serviço de saúde: pescoço $(n=41)$; ombros $(n=32)$; parte superior das costas $(n=24)$; cotovelos $(n=76)$; punhos/mãos $(n=35)$; parte inferior das costas $(n=20)$; quadril/coxas $(n=30)$; joelhos $(n=35)$; tornozelo e pé $(n=44)$.

\section{Discussão}

A mariscagem é uma atividade realizada predominantemente por mulheres. Assim como neste estudo, um outro realizado em uma cidade baiana revelou que $75 \%$ dos indivíduos cadastrados que exerciam a atividade da mariscagem eram do sexo feminino ${ }^{11}$. A predominância das mulheres nessa atividade laboral não é uma especificidade do Brasil, uma vez que um estudo realizado na Galícia, Espanha, revelou que 93,5\% das pessoas que realizavam essa atividade eram mulheres ${ }^{15}$.
Quanto ao perfil demográfico, a distribuição etária das trabalhadoras estudadas, bem como a raça/cor, foi semelhante ao constatado em estudo realizado com marisqueiras atendidas em um serviço de saúde ocupacional de Salvador. O fato de que mulheres negras são maioria entre as trabalhadoras que coletam mariscos reforça o contexto histórico que envolve essa atividade, uma vez que, em sua maioria, essas comunidades têm descendência indígena ou são comunidades remanescentes de quilombos ${ }^{16}$.

A baixa escolaridade e ter um companheiro parecem ser uma realidade para essas trabalhadoras, 
como também identificou um estudo realizado em cinco comunidades de pescadores localizadas na Baía de Todos os Santos, na Bahia. A coleta de mariscos caracteriza-se principalmente por ser um trabalho artesanal, tradicional, de baixa remuneração e escolaridade ${ }^{2}$.

No que diz respeito à renda mensal, a média de remuneração foi superior à encontrada em outros dois estudos $^{2,11}$. Contudo, deve-se destacar que a remuneração é baixa, correspondendo a $25 \%$ do valor do salário mínimo $(\mathrm{R} \$ 937,00)$ vigente no período da coleta dos dados do estudo ${ }^{17}$. A situação se agrava quando se observa que essas trabalhadoras corresidem com em média quatro pessoas, sustentam a casa com o dinheiro que provém da mariscagem e afirmam que esse rendimento é suficiente para sustentar a família.

A renda baixa submete as trabalhadoras a situações de vulnerabilidade socioeconômica e, sobretudo, as impede de adotarem medidas preventivas, como o uso de Equipamentos de Proteção Individual (EPI) e de Equipamentos de Proteção Coletiva (EPC), o que poderia contribuir para diminuir os riscos de agravos à saúde ${ }^{18}$.

Todas residiam em casa própria e de alvenaria, com sistema de saneamento do tipo fossa rudimentar. O saneamento básico constitui-se de uma gama de serviços, que vão desde a infraestrutura e instalações operacionais de abastecimento de água potável até o esgotamento sanitário. No Brasil, o acesso ao saneamento básico é um direito assegurado pela Constituição Federal de 1988, sendo preconizadas sua universalização e integralidade ${ }^{19}$. No entanto, é evidente a limitação na cobertura de alguns desses serviços no país, sobretudo nas regiões Norte e Nordeste $^{20}$.

Condições de saneamento precárias contribuem para o adoecimento das populações. Estudo afirma que serviços ineficientes de saneamento básico, como a persistência de fossa rudimentar, são responsáveis por um número expressivo de internações e óbitos, principalmente no que diz respeito às doenças infectoparasitárias ${ }^{21}$. Além disso, tal situação coloca em risco os mariscos, que tradicionalmente são lavados, cozidos, catados e vendidos no ambiente doméstico, criando, nesse sentido, um contexto que concorre para a contaminação do pescado, resultando na obtenção de produtos com perfil microbiológico e físico-químico inadequados aos padrões de segurança alimentar ${ }^{22}$.

Quanto ao tempo na ocupação, carga horária diária e semanal, pausa para almoço e registro de trabalho formal, com carteira assinada, achados semelhantes aos obtidos foram encontrados em outro estudo, também realizado na Bahia, que objetivou identificar a prevalência dos distúrbios musculoesqueléticos em pescoço/ombro e membros superiores distais, além de seus principais fatores de risco em pescadoras artesanais/catadoras de marisco ${ }^{11}$.

No que diz respeito às condições em que trabalham, os resultados revelam que, embora reconheçam os riscos aos quais estão sujeitas, essas trabalhadoras apontam também a necessidade de garantir a subsistência de sua família e estabelecem uma relação de gratidão com a natureza que lhes proporciona esse recurso. Quanto maior a necessidade de sobrevivência maior a sobrecarga de trabalho ${ }^{23}$.

Manutenção prolongada de certas posturas, movimentos repetitivos e uso de força muscular também foram evidenciados por outros autores que estudaram o processo de trabalho de catadoras de marisco. Em estudo realizado na comunidade pesqueira da Ilha de Maré observou-se que trabalhadoras chegavam a realizar aproximadamente 70 mil movimentos por dia de trabalho, excluindo as etapas de limpeza dos mariscos ${ }^{24}$.

A Norma Regulamentadora do Trabalho $\mathrm{n}^{0} 17$ preconiza que, em casos de atividades que requeiram movimentos repetitivos de mão, a exemplo de atividades de digitação, o número de repetições não ultrapasse 8 mil toques por hora por jornada de seis horas, com um período de descanso de 10 minutos a cada 50 minutos de trabalho ${ }^{25}$.

Quanto ao levantamento de carga, a Consolidação das Leis do Trabalho (CLT), no art. 198, estabelece para o transporte manual de carga o limite de $60 \mathrm{~kg}$ para homens e de $25 \mathrm{~kg}$ para mulhe$\mathrm{res}^{26}$. No entanto, observou-se neste estudo que parte das trabalhadoras transportavam carga superior ao limite preconizado pela CLT.

O manuseio de carga por períodos prolongados está diretamente relacionado a uma série de comprometimentos musculoesqueléticos. No caso das catadoras de marisco, esse manuseio está associado a diversos outros fatores de risco. Essas mulheres geralmente transportam seus mariscos em pé, realizando um trabalho estático dos músculos da cadeia anterior e posterior da coluna a fim de manter o equilíbrio, sem o correto recrutamento dos estabilizadores da coluna para sustentar o balde que em média pesa $24,3 \mathrm{~kg}$. Geralmente esse balde é apoiado sobre a cabeça por um período de 30 a 60 minutos de caminhada e para mantê-lo é necessário que o ombro esteja elevado, exigindo dos músculos trapézio e elevadores da escápula que trabalhem contra a gravidade ${ }^{27}$.

O trabalho das catadoras de marisco envolve sobrecarga muscular/articular e movimentos repetitivos, fatores que favorecem o surgimento das LER/Dort. Essa situação se agrava quando se considera o início precoce e a interrupção tardia dessa atividade laboral ${ }^{28}$. 
Sendo assim, essas mulheres estão sujeitas a riscos relacionados a aspectos ergonômicos em seu processo laboral, sendo necessário elencar três parâmetros para definir os riscos de LER/Dort, conforme descrito na literatura: o primeiro diz respeito ao excesso de movimentos, tanto de motricidade grossa quanto fina. $\mathrm{O}$ segundo refere-se ao excesso de tempo no trabalho com sobrecarga em membros superiores; por fim, a ausência de descanso e o ritmo de trabalho acelerado decorrentes das condições socioeconômicas ${ }^{2}$.

Outros estudos realizados com populações semelhantes revelaram resultados similares quanto aos movimentos repetitivos e ao uso de força, sobretudo em membros superiores ${ }^{4,11,23,24,28}$.

No que diz respeito aos locais dos sintomas musculoesqueléticos, os achados diferem do estudo realizado na Galícia, Espanha, no qual os autores constataram maior prevalência de queixas no pescoço $(70,9 \%)$, seguido pela região lombar $(65,5 \%)$ e pelos ombros $(45,8 \%)^{15}$.

O resultado de queixas na região da coluna vertebral condiz com a biomecânica do processo laboral dessas mulheres que trabalham adotando, em sua maioria, uma postura com flexão de tronco. A principal causa das queixas álgicas na região torácica da coluna se deve à postura com flexão cervical e/ou anteriorização por períodos prolongados, enquanto as dores da região lombar ocorrem principalmente pela perda da lordose fisiológica, acarretando um aumento do ângulo sacral e levando a um estresse no arco posterior, com consequente instabilidade vertebral ${ }^{29}$.

Os segmentos corporais que mais as impossibilitaram de realizar atividades normais foram os punhos e as mãos. Talvez isso se deva a sua função preênsil, primordial para realizar as Atividades de Vida Diária e as Atividades Instrumentais da Vida Diária.

Além disso, estudos prévios evidenciaram que, mesmo com dores em algumas regiões, essas trabalhadoras precisam trabalhar para que sua renda mensal não seja comprometida e, consequentemente, a garantia do sustento de sua família ${ }^{2,30}$.
A vulnerabilidade social impõe um ritmo intenso de trabalho a essas mulheres, fazendo-as acelerar o trabalho de coleta de mariscos, visando gerar mais produtos para venda. Embora o ritmo de trabalho seja autoimposto, quanto mais elas necessitam de renda mais aumenta sua carga de trabalho, mesmo em condições em que o limite físico já é evidente nas queixas álgicas. Essa necessidade faz com que o ritmo de trabalho seja exaustivo, repetitivo e constante, acarretando riscos importantes de LER/Dort ${ }^{31}$.

Este estudo foi realizado com uma população de catadoras de marisco, em local de difícil acesso. As trabalhadoras atuavam no setor informal e sob condições precárias de trabalho, com características laborais bem específicas que influenciavam suas condições de saúde. Também se limitou a descrever as prevalências de sintomas musculoesqueléticos e seus fatores de risco conhecidos, sem testar associações entre exposições e desfechos.

\section{Conclusão}

As catadoras de marisco estudadas estão expostas aos principais riscos relacionados a aspectos ergonômicos para o desenvolvimento de LER/Dort e apresentam elevada prevalência de distúrbios musculoesqueléticos. Predominaram queixas musculoesqueléticas nas regiões superior e inferior da coluna. Observaram-se limitações à realização das atividades diárias devido à dor em punhos e mãos.

Os distúrbios musculoesqueléticos refletem-se na capacidade dos indivíduos de produzir força para o trabalho. Sendo assim, é verossímil supor que impactem de forma considerável as condições socioeconômicas das catadoras de marisco e de suas famílias, à medida que essas trabalhadoras dependem do bom condicionamento físico para manter suas atividades laborais.

\section{Contribuições de autoria}

Silva RA e Nery AA participaram do delineamento do projeto, coleta e análise dos dados, elaboração e revisão crítica do manuscrito. Pena PGL, Rios MA e Paula R participaram da elaboração e revisão crítica do manuscrito. Todos os autores participaram da aprovação final da versão publicada e assumem igual responsabilidade por seu conteúdo. 


\section{Referências}

1. Rios AO, Rego RCF, Pena PGL. Doenças em trabalhadores da pesca. Rev Baiana Saude Publica. 2011;35(1):175-88.

2. Brasil. Ministério da Pesca e Aquicultura. O diagnóstico da pesca extrativa no Brasil [Internet]. Brasília, DF; 2012 [citado em 27 maio 2021]. Disponível em: https://www.icmbio.gov.br/cepsul/ images/stories/biblioteca/download/estatistica/ est_2010_nac_boletim.pdf

3. Pena PGL, Martins VLA, organizadores. Sofrimento negligenciado: doenças do trabalho em marisqueiras e pescadores artesanais. Salvador: Edufba; 2014.

4. Pena PGL, Martins V, Rego RF. Por uma política para a saúde do trabalhador não assalariado: o caso dos pescadores artesanais e das marisqueiras. Rev Bras Saude Ocup. 2013;38(127):57-68.

5. Charles, A. Good practices in the governance of small-scale fisheries with a focus on rights-based approaches. In: Pomeroy RS, Andrew N, editores. Small-scale fisheries management: frameworks and approaches for the developing world. Oxford: CABI; 2010. p. 1-23.

6. Rodríguez-Romero B, Pita-Fernández S, Carballo-Costa L. Impact of physical and psychosocial factores on disability caused by lumbar pain amongst fishing sector workers. Rheumatol Int. 2013;33(7):1769-78.

7. Mascarenhas CHM, Prado FO, Fernandes MH. Dor musculoesquelética e qualidade de vida em agentes comunitários de saúde. Rev Saude Publica. 2012;14(4):668-80.

8. Brasil. Ministério da Previdência Social. Anuário estatístico de acidentes do trabalho 2015. Quantidade de acidentes do trabalho, por situação de registro e motivo, segundo os 200 códigos da Classificação Internacional de Doenças - CID10 mais incidentes, no Brasil - 2015 [Internet]. Brasília, DF; 2015 [citado em 27 maio 2021]. Disponível em: http://sa.previdencia.gov.br/ site/2017/05/aeat15.pdf

9. Costa BR, Vieira ER. Risk factors for work-related musculoskeletal disorders: a systematic review of recent longitudinal studies. Am J Ind Med. 2010;53(3):285-323.

10. Barbosa REC, Assunção AA, Araújo TM. Distúrbios musculoesqueléticos em trabalhadores do setor saúde de Belo Horizonte, Minas Gerais, Brasil. Cad Saude Publica. 2012;28(8):1569-80.

11. Falcão IR, Couto MCBM, Lima VMC, Pena PGL, Andrade LL, Müller JS, et al. Prevalência dos distúrbios musculoesqueléticos nos membros superiores e pescoço em pescadoras artesanais/ marisqueiras em Saubara, Bahia, Brasil. Cienc Saude Colet. 2015;20(8):2469-80.

12. Fragoso JR, Borges GF, Carvalho MLO, Ramos MS. Musculoskeletal disorders in countryside fishermen of Amazonas-Brazil. Mundo Saude. 2018;42(1):248-65.

13. Barros ENC, Alexandre NMC. Cross-cultural adaptation of the Nordic musculoskeletal questionnaire. Int Nurs Rev. 2003;50(2):101-8.

14. World Health Organization. Obesity: preventing and managing the global epidemic. Report of a World Health Organization Consultation. Geneva; 2000.

15. Rodríguez-Romero B, Pita-Fernández S, Raposo-Vidal I, Seoane-Pillado T. Prevalence, co-occurrence, and predictive factors for musculoskeletal pain among shellfish gatherers. Clin Rheumatol. 2012;31(2):283-92.

16. Martins VLA. Doenças do trabalho em marisqueiras segundo casuística do Serviço de Saúde Ocupacional do Hospital Universitário Professor Edgar Santos (Hupes), Bahia. In: Pena PGL, Martins VLA, organizadores. Sofrimento negligenciado doenças do trabalho em marisqueiras e pescadoras artesanais. Salvador: Edufba; 2014. p. 255-70.

17. Departamento Intersindical de Estatística e Estudos Econômico. Salário mínimo nominal e necessário [Internet]. São Paulo; [data desconhecida] [citado em 27 maio 2021]. Disponível em: https://www.dieese.org.br/ analisecestabasica/salarioMinimo.html

18. Cavalcante ES, Pessoa JM Jr, Freire ILS, Faro ACM, Torres GV, Miranda FAN. Spinal cord injury due to diving accidents and stress among artisanal fishers. Texto Contexto Enferm. 2017;26(2):e00190016.

19. Brasil. Lei $\mathrm{n}^{\mathrm{O}} 11.445$, de 5 de janeiro de 2007. Diário Oficial da União. 8 jan 2007.

20. Instituto Brasileiro de Geografia e Estatística. Censo demográfico 2010: características da população e dos domicílios - resultados do universo. Rio de Janeiro; 2012.

21. Teixeira JC, Gomes MHR, Souza JA. Associação entre cobertura por serviços de saneamento e indicadores epidemiológicos nos países da América Latina: estudo com dados secundários. Rev Panam Salud Publica. 2012;32(6):419-25.

22. Nóbrega GS, Cardoso RCV, Furtunato DMN, Góes JAW, Ferreira TCB, Santos MDF, et al. Formação para marisqueiras em segurança de alimentos e saúde do trabalhador: uma experiência na comunidade de Ilha do Paty, Bahia, Brasil. Cienc Saude Colet. 2014;19(5):1561-71.

23. Pena PGL, Freitas MCS, Cardim A. Trabalho artesanal, cadências infernais e lesões por esforços repetitivos: estudo de caso em uma comunidade de mariscadeiras na Ilha de Maré, Bahia. Cienc Saude Colet. 2011;16(8):3383-92.

24. Pena PGL, Freitas MCS. Condições de trabalho da pesca artesanal de mariscos e riscos para LER/ DORT em uma comunidade pesqueira da Ilha de 
Maré. In: Pena PGL, Martins VLA, organizadores. Sofrimento negligenciado: doenças do trabalho em marisqueiras e pescadoras artesanais. Salvador: Edufba; 2014. p. 53-91.

25. Brasil. Ministério do Trabalho e Emprego. Secretaria de Segurança e Saúde no Trabalho. Norma regulamentadora - NR17 - Ergonomia [Internet]. Brasília, DF; 1978 [citado em 27 maio 2021]. Disponível em: https://www.gov. br/trabalho/pt-br/inspecao/seguranca-e-saude-notrabalho/normas-regulamentadoras/nr-17.pdf/view

26. Brasil. Ministério do Trabalho. Lei $n^{\circ} 6514$, de 22 de dezembro de 1977. Diário Oficial da União [Internet]. 22 dez 1977 [citado em 24 jan 2021]. Disponível em: http://www.planalto.gov.br/ ccivil_03/leis/l6514.htm

27. Martins VLA, Pena PGL, Gomes TMD, Seixas JM, Pinho MC, Lemos IM. Protocolo sobre LER/ DORT em pescadoras e pescadores artesanais nas atividades de mariscagem. In: Pena PGL, Martins VLA, organizadores. Sofrimento negligenciado: doenças do trabalho em marisqueiras e pescadoras artesanais. Salvador: Edufba; 2014. p. 197-224.

28. Pena PGL, Gomez CM. Saúde dos pescadores artesanais e desafios para a Vigilância em Saúde do Trabalhador. Cienc Saude Colet. 2014;19(12):4689-98.

29. Neumann DA. Cinesiologia do aparelho musculoesquelético: fundamentos para a reabilitação física. 2a ed. Rio de Janeiro: Elsevier; 2011.

30. Müller JS, Falcão IR, Couto MCBM, Viana WS, Alves IB, Viola DN, et al. Health-related quality of life among artisanal fisherwomen/shellfish gath-erers: lower than the general population. Int J Environ Res Public Health. 2016;13(5):466.

31. Müller JS, Falcão IR, Couto MCBM, Viana WS, Alves IB, Viola DN, et al. Artisanal fisherwomen/ shellfish gatherers: analyzing the impact of upper limb functioning and disability on health-related quality of life. Cienc Saude Colet. 2017;22(11):3635-44. 